\title{
Mean circulation in the coastal ocean off northeastern North America from a regional-scale ocean model
}

\author{
K. Chen ${ }^{1}$ and R. He ${ }^{2}$ \\ ${ }^{1}$ Physical Oceanography Department, Woods Hole Oceanographic Institution, \\ 266 Woods Hole Road, MS\# 21, Woods Hole, MA 02543, USA \\ ${ }^{2}$ Department of Marine, Earth \& Atmosphere Sciences, North Carolina State University, \\ 2800 Faucette Drive, Raleigh, NC 27695, USA \\ Correspondence to: K. Chen (kchen@whoi.edu)
}

Received: 27 October 2014 - Published in Ocean Sci. Discuss.: 08 December 2014

Revised: 28 April 2015 - Accepted: 05 June 2015 - Published: 03 July 2015

\begin{abstract}
A regional-scale ocean model was used to hindcast the coastal circulation over the Middle Atlantic Bight (MAB) and Gulf of Maine (GOM) from 2004 to 2013. The model was nested inside a data assimilative global ocean model that provided initial and open boundary conditions. Realistic atmospheric forcing, tides and observed river runoff were also used to drive the model. Hindcast solutions were compared against observations, which included coastal sea levels, satellite altimetry sea surface height, in situ temperature and salinity measurements in the GOM, and observed mean depth-averaged velocities. Good agreements with observations suggest that the hindcast model is capable of capturing the major circulation variability in the MAB and GOM. Time- and space-continuous hindcast fields were used to depict the mean circulation, along- and cross-shelf transport and the associated momentum balances. The hindcast confirms the presence of the equatorward mean shelf circulation, which varies from $2.33 \mathrm{~Sv}$ over the Scotian Shelf to $0.22 \mathrm{~Sv}$ near Cape Hatteras. Using the $200 \mathrm{~m}$ isobath as the shelf/slope boundary, the mean cross-shelf transport calculations indicate that the shelfbreak segments off the Gulf of Maine (including the southern flank of Georges Bank and the Northeast Channel) and Cape Hatteras are the major sites for shelf water export. The momentum analysis reveals that the along-shelf sea level difference from Nova Scotia to Cape Hatteras is about $0.36 \mathrm{~m}$. The nonlinear advection, stress, and horizontal viscosity terms all contribute to the ageostrophic circulation in the along-isobath direction, whereas the nonlinear advection plays a dominant role in determining the ageostrophic current in the cross-isobath direction.
\end{abstract}

\section{Introduction}

The northeastern coast of North America borders the Atlantic Ocean, with a continental shelf extending over $5000 \mathrm{~km}$. For our purpose, we focus on the coastal segment between Cape Hatteras in the southwest and Nova Scotia in the northeast (Fig. 1). The shelf width and depth here are typically 100 $200 \mathrm{~km}$ and 100-200 m, respectively, but there are significant regional variations associated with coastline indentations by gulfs and with submarine banks and basins. From a North Atlantic basin-scale circulation point of view, this segment lies in the western boundary confluence zone, with the subpolar gyre and the Labrador Current/Scotian Shelf waters moving south and the subtropical gyre and the Gulf Stream moving north, constituting a unique setting for a wide range of important interdisciplinary oceanographic and environmental management issues.

Isotope analyses indicate that the equatorward flow of subpolar water has a major influence on this coastal region (Chapman and Beardsley, 1989). The annual mean shelf water transport estimated by Loder et al. (1998) shows that there is a systematic reduction in shelfbreak transport, varying roughly from $7.5 \mathrm{~Sv}$ in the Labrador Sea to $0.7 \mathrm{~Sv}$ off Nova Scotia. There are further reductions in net transport as Scotian shelf and slope waters enter the Gulf of Maine (GOM) and subsequently move into the Middle Atlantic Bight (MAB). The circulation in the GOM is strongly steered by the bottom topography, with a cyclonic flow around the gulf's inner basins and an anticyclonic flow around its outer bank (e.g., Brooks, 1985). The circulation 


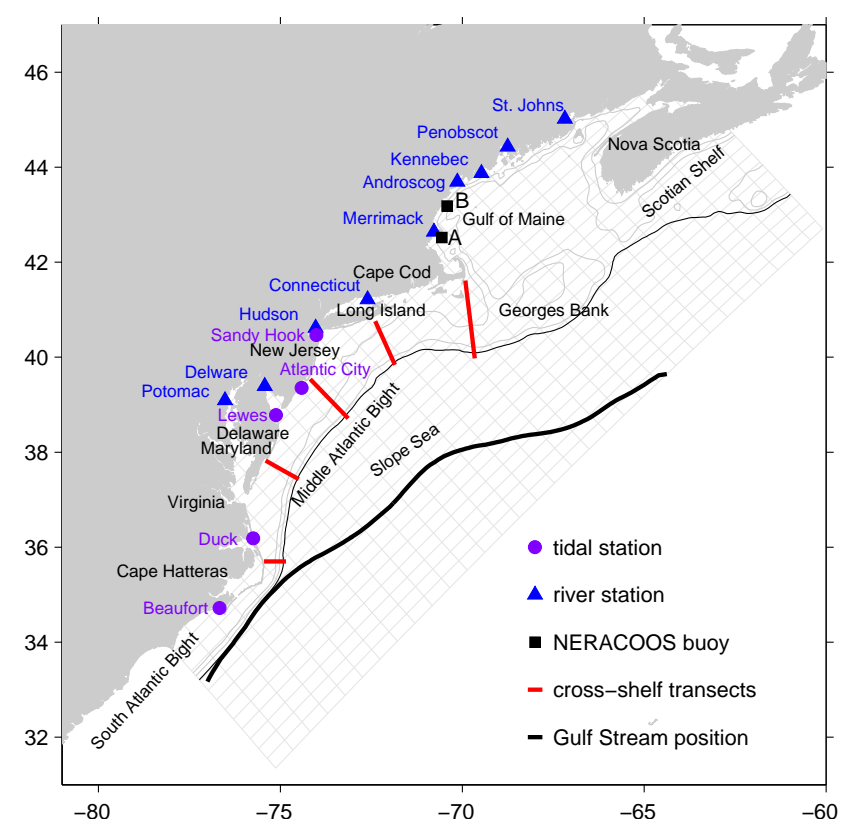

Figure 1. The MABGOM model grid (light gray, plotted every five grid points) and locations of coastal sea level stations (purple circle), USGS river gauges (blue triangle), NERACOOS buoys (black square), and cross-shelf transects (red line) where the circulation was sampled, as discussed in Sect. 3.2.2. The black dashed line denotes the mean path of Gulf Stream, determined by the $15^{\circ} \mathrm{C}$ isotherm at $200 \mathrm{~m}$ (Joyce et al., 2000). The 50 and $100 \mathrm{~m}$ isobaths are shown in light gray, and the $200 \mathrm{~m}$ isobath is plotted in black. Geographic locations discussed in the text are also shown.

becomes more uniform in the MAB, with southwestward flow on the inner shelf (e.g., Beardsley and Boicourt, 1981). Further downstream, the mean equatorward transport continues decreasing as it approaches Cape Hatteras (Loder et al., 1998).

Such equatorward transport is accompanied by important yet highly complex cross-shelf transport between the shelf sea and the Slope Sea. The latter is an admixture of waters of subpolar and subtropical origins, forming a buffer zone between the Gulf Stream and the near-shore coastal ocean. Several processes have been identified as important contributors to the cross-shelf exchange, the most dramatic being Gulf Stream ring interactions with the shelf/slope front. For example, Joyce et al. (1992) indicated that a single ring acting over a short time span (a couple of months) can account for the entire annual shelf-ocean transport and flux exchange. Shelfbreak frontal eddies associated with rings (e.g., Houghton et al., 1986), baroclinic instability and frontal meandering (Garvine et al., 1988; Gawarkiewicz et al., 2004) and topography and channels (e.g., Churchill et al., 1986; Ramp et al., 1985) also significantly affect the shelf-ocean exchange.

Quantifying along-shelf transport and cross-shelf exchange and their seasonal variations in this area is the key to understanding and quantifying the distribution of mate- rial properties, such as heat, salt, nutrient and carbon fluxes that are vital to MAB and GOM coastal ecosystem dynamics (e.g., Walsh et al., 1988). Although several long-term records of coastal current measurements have been obtained over the study area, the different conditions during the observational periods made it difficult to reach a consistent conclusion on spatial and temporal variations of shelf circulation. For instance, the seasonal reversal of the slope current observed in the Nantucket Shoals Flux Experiment (NSFE79) (Beardsley et al., 1985) was not apparent in the Shelf Edge Exchange Processes (SEEP-I) experiment (Aikman et al., 1988). Those 1- or 2-year long records are too short to compute an accurate annual mean and seasonal cycle, or to study the interannual variations. In this regard, an important step forward was made recently by Lentz (2008a). Utilizing 27 historical velocity time series from the MAB, each being longer than 200 days, this study confirmed a consistent equatorward mean circulation over the MAB continental shelf. The mean cross-shelf flow is typically offshore near the surface and onshore at depth. Near the bottom, the cross-shelf flow increases with increasing water depth from coast to shelf slope, with the change in direction at the $50 \mathrm{~m}$ isobath. Furthermore, Lentz (2008b) studied the shelf circulation seasonal variation using a subset of the same velocity data, and identified significant variations in the along-shelf circulation, which is related to seasonal variations in the wind stress and the cross-shelf density gradient. Although observations presented in these two recent studies provide a remarkably consistent picture of MAB circulation, Lentz (2008a) also noted that the spatial coverage of the current observations is still very sparse and uneven. While the results suggest the important roles of along-shelf pressure gradient and bottom stress, direct measurements are very difficult to achieve due to large observational uncertainties. In an effort to understand the origin of the along-shelf pressure gradient (ASPG) in the MAB, $\mathrm{Xu}$ and Oey (2011) estimated the mean ASPG is about 5$8 \times 10^{-8}$ in the MAB. They also suggested that river and coastal Labrador sea waters transport contribute to the positive mean along-shelf pressure gradient (ASPG, tilting up northward), whereas wind and Gulf Stream tend to produce a negative mean ASPG. Seasonal and interannual variation of ASPG correlate with the Gulf Stream shift and eddy kinetic energy (EKE) north of the Gulf Stream due to warm core rings. While providing important insights to the ASPG, their conclusion was primarily based on a set of idealized numerical experiments. These studies call for a more complete shelf-wide, nested, primitive equation numerical modeling study to provide insight into shelf circulation dynamics.

The scientific objective of this study is to characterize the mean circulation and its associated dynamics in the coastal ocean off northeastern North America, with a focus on alongand cross-shelf transport in the MAB and GOM. To achieve such an objective and circumvent limitations of sparse observations, we perform a 10 -year regional circulation hindcast using a state-of-the-art ocean model. The work described in 
this study and the resulting 10-year three-dimensional circulation fields are the first step in addressing other important shelf processes including inter-annual variability of the circulation and marine ecosystem dynamics in the northeastern US coastal ocean.

We begin in Sect. 2 with a description of the regionalscale, nested circulation model used in this study. Section 3 provides model skill assessments by gauging simulations against various in situ and satellite observations. Based on these comparisons, we provide more detailed analysis of MABGOM shelf circulation, alongshore and cross-shelf transport estimates in Sect. 4, followed by the discussion and summary in Sect. 5.

\section{Model}

Our coastal circulation simulation was performed with the Regional Ocean Modeling System (ROMS), a free-surface, hydrostatic, primitive-equation model in widespread use for estuarine, coastal and basin-scale ocean applications (www.myroms.org/papers). ROMS is formulated in vertically stretched, terrain-following coordinates using algorithms described in detail by Shchepetkin and McWilliams (1998, 2003, 2005). Its computational kernel includes highorder advection and time-stepping schemes, weighted temporal averaging of the barotropic mode to reduce aliasing into the slow baroclinic motions, and conservative parabolic splines for vertical discretization. A redefinition of the barotropic pressure-gradient term is also applied in ROMS to reduce the pressure-gradient truncation error, which has previously limited the accuracy of terrain-following coordinate models. The model domain encompasses both the Middle Atlantic Bight and Gulf of Maine (hereinafter, MABGOM), bounded by Cape Hatteras in the southwest and Nova Scotia in the northeast. The horizontal resolution varies from 6 to $10 \mathrm{~km}$. There are 36 terrain-following vertical levels, with higher resolution near the surface and bottom in order to better resolve ocean boundary layers.

\subsection{Open boundary and initial conditions}

To specify the open boundary conditions for the MABGOM model, we nested it inside the global ocean simulation provided by HYCOM/NCODA (Hybrid Coordinate Ocean Model/NRL Coupled Ocean Data Assimilation: http: //HYCOM.org). NCODA is a multivariate optimal interpolation technique that assimilates surface observations from satellites, including altimeter and multi-channel sea surface temperature, and also profile data such as expendable bathythermographs (XBTs), conductivity-temperaturedepth (CTDs) and ARGO floats (Chassignet et al., 2006). As a part of the Global Ocean Data Assimilation Experiment (GODAE), HYCOM/NCODA provides daily threedimensional ocean state estimates at $1 / 12^{\circ}$ resolution. Because the domain of MABGOM model covers a significant potion of the Slope Sea, where active Gulf Stream meanders and slope water eddies often occur, HYCOM/NCODA fields are very appealing for our regional-scale coastal circulation simulation in that the timing and extent of such open ocean processes can be well represented through data assimilation.

A one-way nesting approach was used to downscale HYCOM/NCODA ("parent model") to the regional-scale MABGOM model ("child model"). Specifically, open boundary conditions (OBCs) were applied to ROMS tracers and baroclinic velocity following the method of Marchesiello et al. (2001), whereby Orlanski-type radiation conditions were used in conjunction with relaxation (with timescales of 0.5 days on inflow and 10 days on outflow) to HYCOM/NCODA solutions. The free surface and depthaveraged velocity boundary conditions were specified using the method of Flather (1976) with the external values defined by HYCOM/NCODA plus $\mathrm{M}_{2}$ tidal harmonics from an ADCIRC simulation of the western Atlantic (Luettich et al., 1992). The latter $\mathrm{M}_{2}$ information provides needed tidal mixing, which is an important element of the regional circulation, particularly in the GOM. We applied the method of Mellor and Yamada (1982) to compute vertical turbulent mixing. Harmonic horizontal diffusion/viscosity for tracer/momentum with a constant value of $20 / 100 \mathrm{~m}^{2} \mathrm{~s}^{-1}$ and the quadratic drag formulation for the bottom friction specification with a drag coefficient of $3 \times 10^{-3}$ were adopted.

One caveat we identified during the course of MABGOM model implementation is coastal hydrography biases in the HYCOM solution. When compared with $0.25^{\circ} \times 0.25^{\circ}$ HydroBase Hydrographic climatology (Curry, 2001), HYCOM/NCODA fields were found to overestimate the coastal salinity field due to the lack of a riverine freshwater input. For instance, HYCOM surface (the 36th layer) mean (averaged between 01 January 2004 and 31 December 2013) salinity is up to 1 (6) unit(s) higher on the shelf (at major river mouths) than the corresponding HydroBase salinity values (Fig. 2). Surface temperature differences between the HYCOM and HydroBase are seen as well. Compared to HydroBase, HYCOM mean overestimates surface temperature, and the misfits vary from $\sim 0$ to $4^{\circ} \mathrm{C}$. Some discrepancies between the two may be due to the different averaging period, and also be due to the difference in their spatial resolution. Together, biases in salinity and temperature fields lead to a bias in the density field, which in turn results in biases in the alongshore and cross-shelf pressure gradients. To correct for such mean biases, we replaced the HYCOM three-dimensional annual mean salinity and temperature fields with the corresponding HydroBase annual means. That is:

$$
\begin{aligned}
& T_{\text {correction }}=T_{\text {hycom }}-\bar{T}_{\text {hycom }}+\bar{T}_{\text {hydrobase }} \\
& S_{\text {correction }}=S_{\text {hycom }}-\bar{S}_{\text {hycom }}+\bar{S}_{\text {hydrobase }}
\end{aligned}
$$

Our premise is that, while the annual means of HYCOM state variables may be biased, their daily, small spatial-scale 

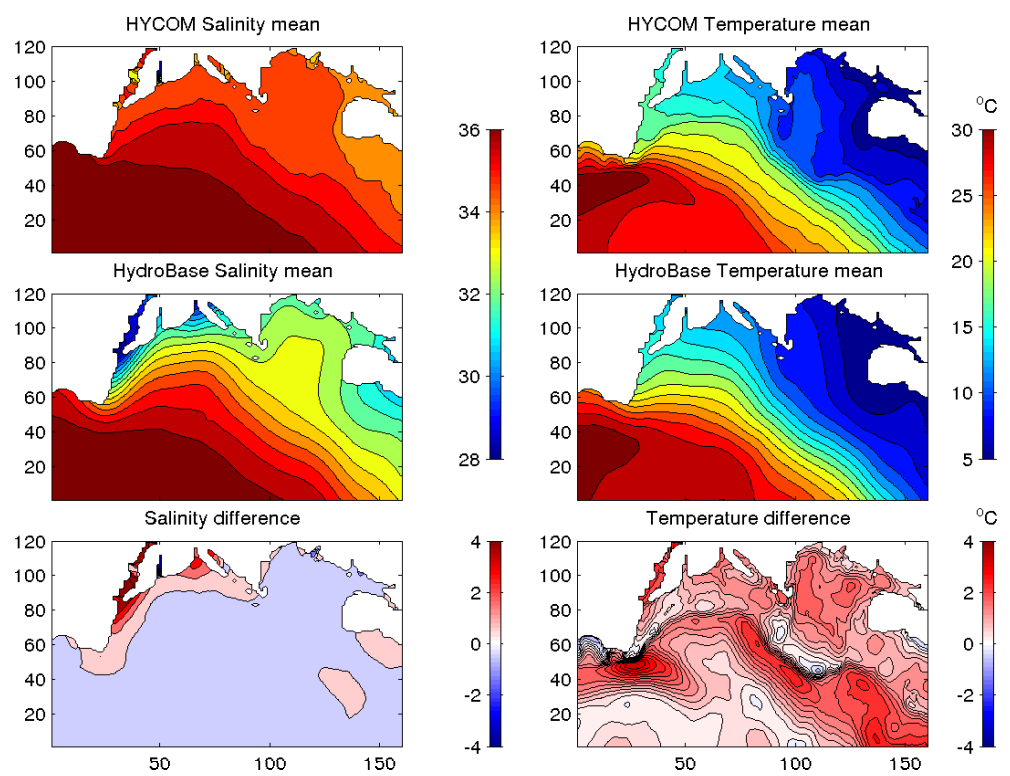

Figure 2. Comparisons of surface (layer 36) salinity and temperature fields between HYCOM/NCODA (top panels) and HydroBase (midpanels), and their misfits (bottom panels). $x$ and $y$ axes denote grid numbers of the model.

variations of temperature and salinity are still important values to account for the coastal circulation variability that we are interested in. Because both ocean sea surface height and transport respond to changes in the density fields, the HydroBase annual mean salinity ( $\left.\bar{S}_{\text {hydrobase }}\right)$ and temperature ( $\left.\bar{T}_{\text {hydrobase }}\right)$ fields were also used to compute the mean dynamic height $(\mathrm{DH})$ and its associated geostrophic transport in the MABGOM model domain. Specifically, DH was obtained by integrating the dynamic anomaly relative to the offshore starting point of each cross-shelf section of the model (Fig. 1). Following the method of Csanady (1976) and Loder et al. (1997), the geostrophic velocity was then computed to balance the local depth-varying pressure gradient that gives zero pressure gradient at the seafloor. Mean DH and geostrophic transport values resulting from this procedure were sampled along the three open boundaries of the MABGOM model and subsequently used to correct HYCOM/NCODA mean sea-level and transport values in the same manner as Eq. (1). Finally, the resulting adjusted boundary sea level and transport values were applied in MABGOM model simulation through the Flather (1976) boundary condition described above. This procedure effectively removed biases in HYCOM/NCODA mean salinity, temperature, sea level and transport fields, while preserving important high-frequency variability in these state variables.

\subsection{Surface forcing}

We utilized surface atmospheric conditions from North America Regional Reanalysis (NARR) provided by NOAA NCEP. The spatial and temporal resolutions of NARR are $35 \mathrm{~km}$ and 3-hourly, respectively. Air-sea fluxes of momen- tum and buoyancy were computed by applying the standard bulk formulae (Fairall et al., 2003) to NARR marine boundary layer winds, air temperature, relative humidity, and air pressure, along with ROMS-generated surface currents. To further constrain the net surface heat flux, we implemented a thermal relaxation term following $\mathrm{He}$ and Weisberg (2002), such that

$K_{\mathrm{H}} \frac{\partial T}{\partial Z}=\frac{Q}{\rho C_{p}}+c\left(T_{\mathrm{obs}}-T_{\mathrm{mod}}\right)$,

where $c=0.5 \mathrm{day}^{-1}$, and $T_{\mathrm{obs}}$ is the daily $0.1^{\circ}$ resolution blended cloud-free surface temperature field generated by the NOAA Coast Watch.

In addition, freshwater (salinity $=0$ unit) outflow from nine major rivers in the MABGOM area was considered (Fig. 1). These include the St. Johns, Penobscot, Kennebec, Androscoggin, Merrimack, Connecticut, Hudson, Delaware, and Potomac Rivers. For each, the transport was specified using the volume time series measured by a river gauge from United State Geological Survey (USGS).

We started the MABGOM model hindcast on 1 November 2003 and ran the simulation continuously until 31 December 2013. Initial hydrodynamic conditions for the hindcast were taken from bias-adjusted HYCOM/NCODA fields on 1 November 2003.

\section{Results}

Standard circulation state variables (sea level, currents, temperature, and salinity) were archived daily. Animations of modeled sea level, surface current, surface temperature and salinity fields display complex spatial and temporal variabil- 

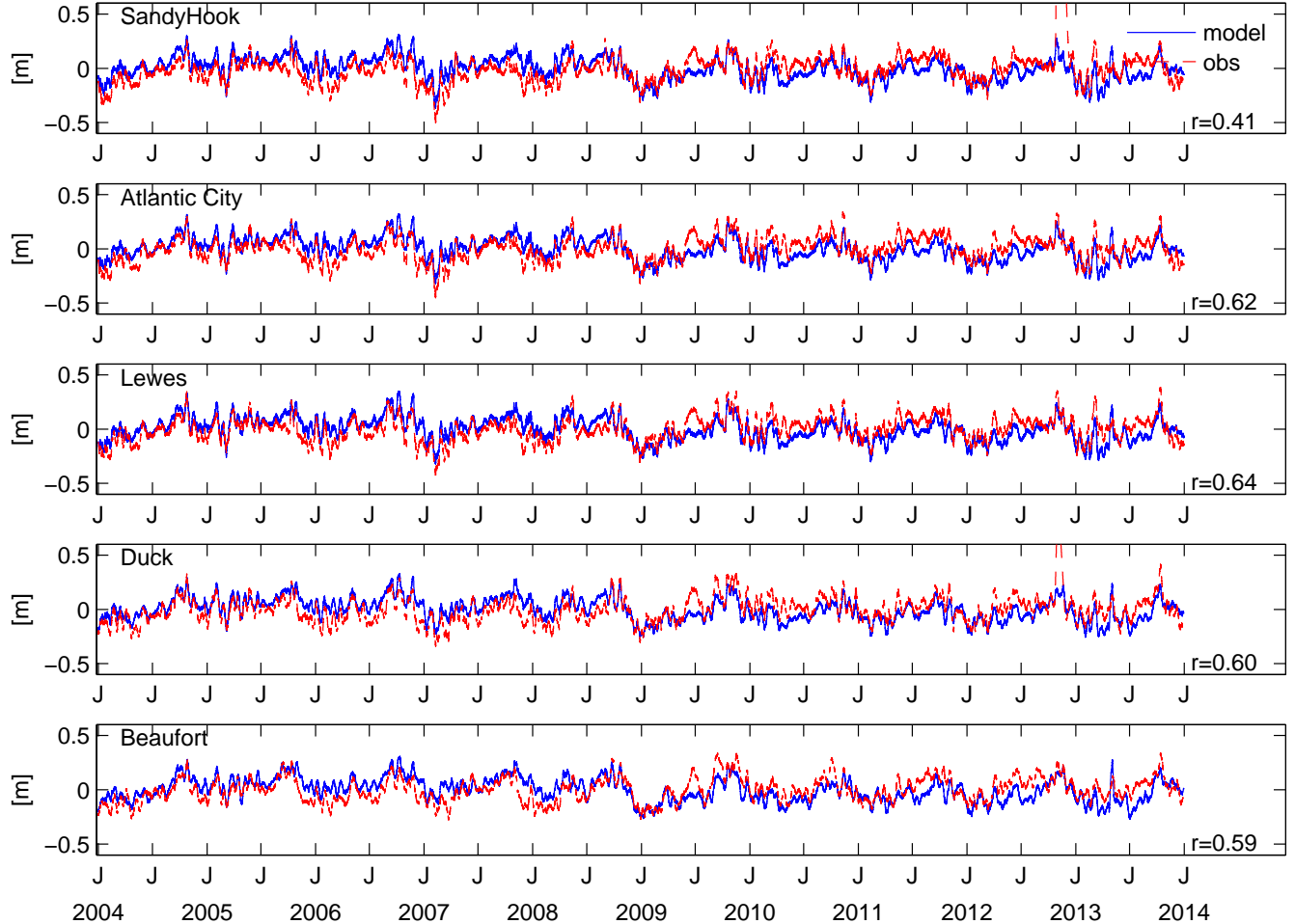

Figure 3. Comparisons of modeled and observed coastal sea levels. Time series are all 10-day low-pass filtered. The correlation coefficient ( $r$, above with $95 \%$ confidence level) is also included for each comparison.

ity, highlighting the synergy of using realistic model simulations in conjunction with in situ observations to study coastal ocean processes. For the model skill assessments and analyses described below, we concentrated on the 10 full years of model hindcast solutions spanning from 1 January 2004 to 31 December 2013.

\subsection{Model skill assessment}

\subsubsection{Coastal sea level}

Because the material property transport in the coastal region is largely determined by sub-tidal circulation, we focus on examining the model's fidelity in reproducing sub-tidal variability. Point-by-point sea-level comparisons were made at five coastal tide gauges that can be resolved by MABGOM model grid resolution (Fig. 3). For clarity, the high-frequency variability was removed from both modeled and observed 10year long sea level time series with a 10-day low-pass filter. Direct comparisons show the model is able to resolve sea level variations reasonably well through the course of simulation. At the $95 \%$ confidence level, the correlation coefficients between the two are above 0.40 at all these stations. Both wind-driven Ekman dynamics (Gill, 1990) and continental shelf wave dynamics (Brink, 1991) dominate coastal sea level variations. The model-data agreements in coastal sea levels suggest the model is faithfully capturing these dynamics.

\subsubsection{Satellite altimeter data}

The model skill in reproducing the shelf-wide sea surface height (SSH) distribution can be examined by comparing to satellite altimeter data. Although altimetry observations have large uncertainties nearshore due to problems such as tidal aliasing, they constitute extremely valuable observations of sea level for the outer shelf and deep-sea regions. We downloaded the $1 / 3^{\circ} \times 1 / 3^{\circ}$ absolute $\mathrm{SSH}$ product from the French Archiving, Validation and Interpolation of Satellite Oceanographic Data (AVISO) (Rio and Hernandez, 2004) and mapped them for the MABGOM region. Because the temporal interval of AVISO data is 1 day, MABGOM model SSH solutions (averaged over the M2 tidal cycle, $\sim 12.42 \mathrm{~h}$ ) were sampled at the times when altimeter data were available. The respective SSH standard deviations (SDs) were then computed to quantify their corresponding sea level variability. SSH SD comparisons (Fig. 4) reveal that the MABGOM model underestimates the magnitude of observed sea level variations, but captures its spatial distribution very well. Both AVISO and ROMS indicate that large SSH SDs with a magnitude of up to about $0.4 \mathrm{~m}$ are present in the Slope Sea. This is the region where energetic meanders and eddies often 

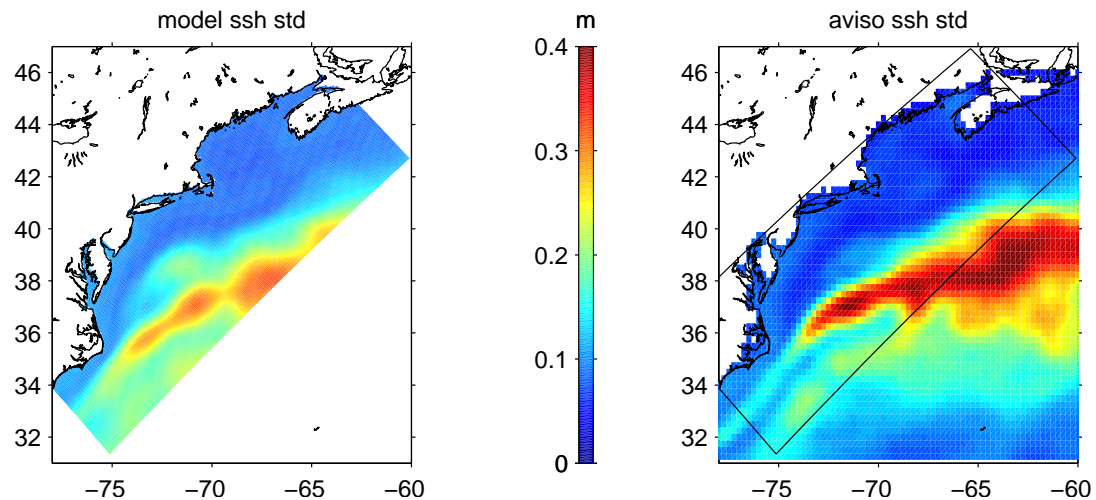

Figure 4. Comparison of altimeter-observed and model-simulated sea surface height standard deviation for the period from January 2004 to December 2013. Spatial correlation between the results of model and AVISO is 0.89 .
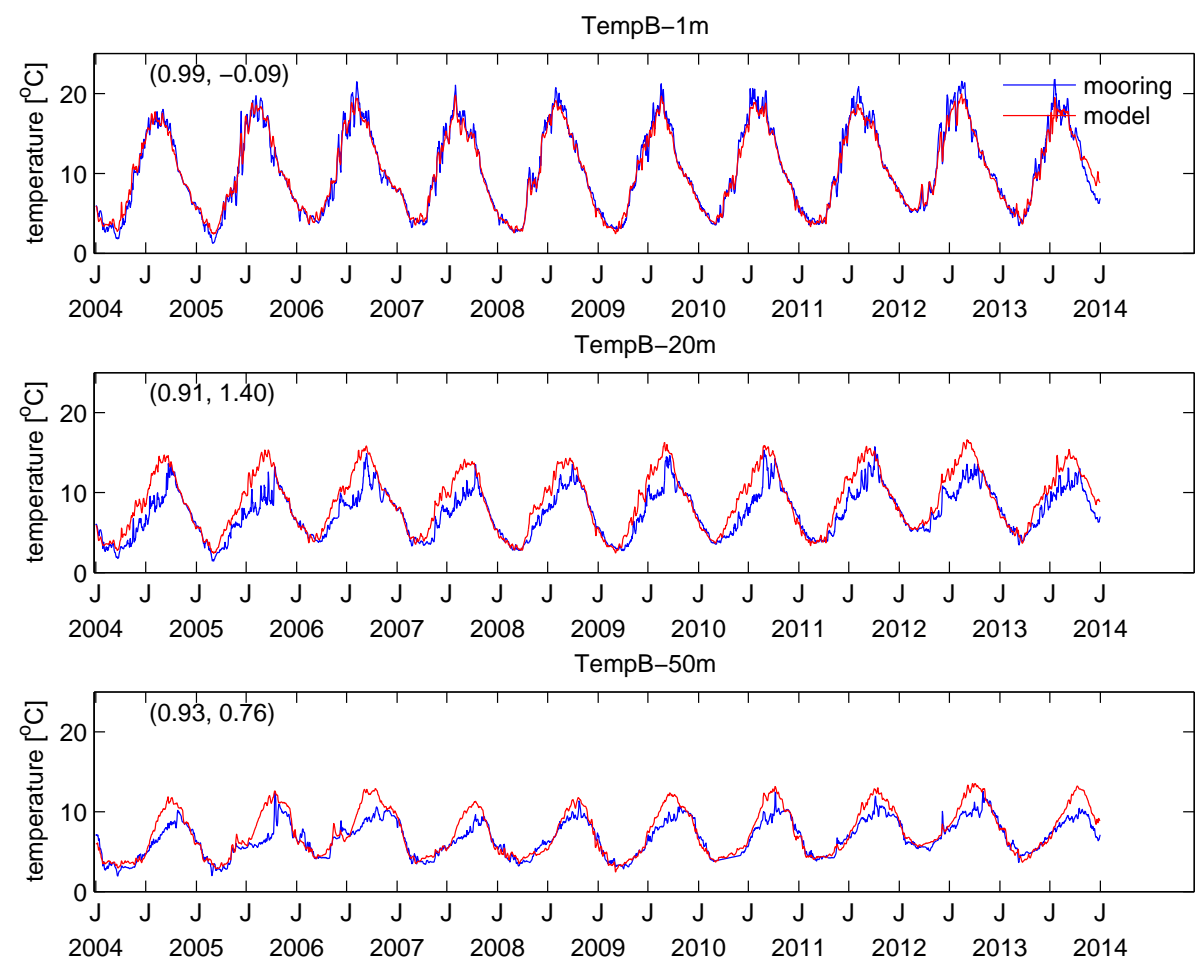

Figure 5. Comparison of observed (mooring) and simulated temperature time series at NERACOOS mooring B. Linear correlation coefficients $(r)$ and mean bias $(b)$ are shown in parentheses $(r, b)$, respectively, in each panel.

occur, exerting a strong offshore influence on the MABGOM shelf circulation (Joyce et al., 1992).

\subsubsection{Mooring data}

We next examined the model with hydrographic data observed by moorings of the Northeastern Regional Association of Coastal Ocean Observing System (NERACOOS, http://www.neracoos.org). Most of the NERACOOS mooring data cover the period from July 2001 to the present, providing a valuable time series for assessing the model's skill in reproducing hydrographic variability. We have com- pared the model solutions against temperature and salinity recorded at multiple buoys. Figures 5 and 6 for example show the results at NERACOOS buoy B, which is located in the western GoM. Temperature comparisons between the simulation and in situ measurements at $-2,-20$ and $-50 \mathrm{~m}$ (Fig. 5) show agreement, with correlation coefficients being $>0.9$ at all three depths. Similar model-data agreement was also seen at NERACOOS buoy A and other available stations. Admittedly, the surface heat flux relaxation scheme described in Sect. 2.2 largely constrains surface temperature $(-2 \mathrm{~m})$. But the temperature evolution at deeper depths (i.e., 

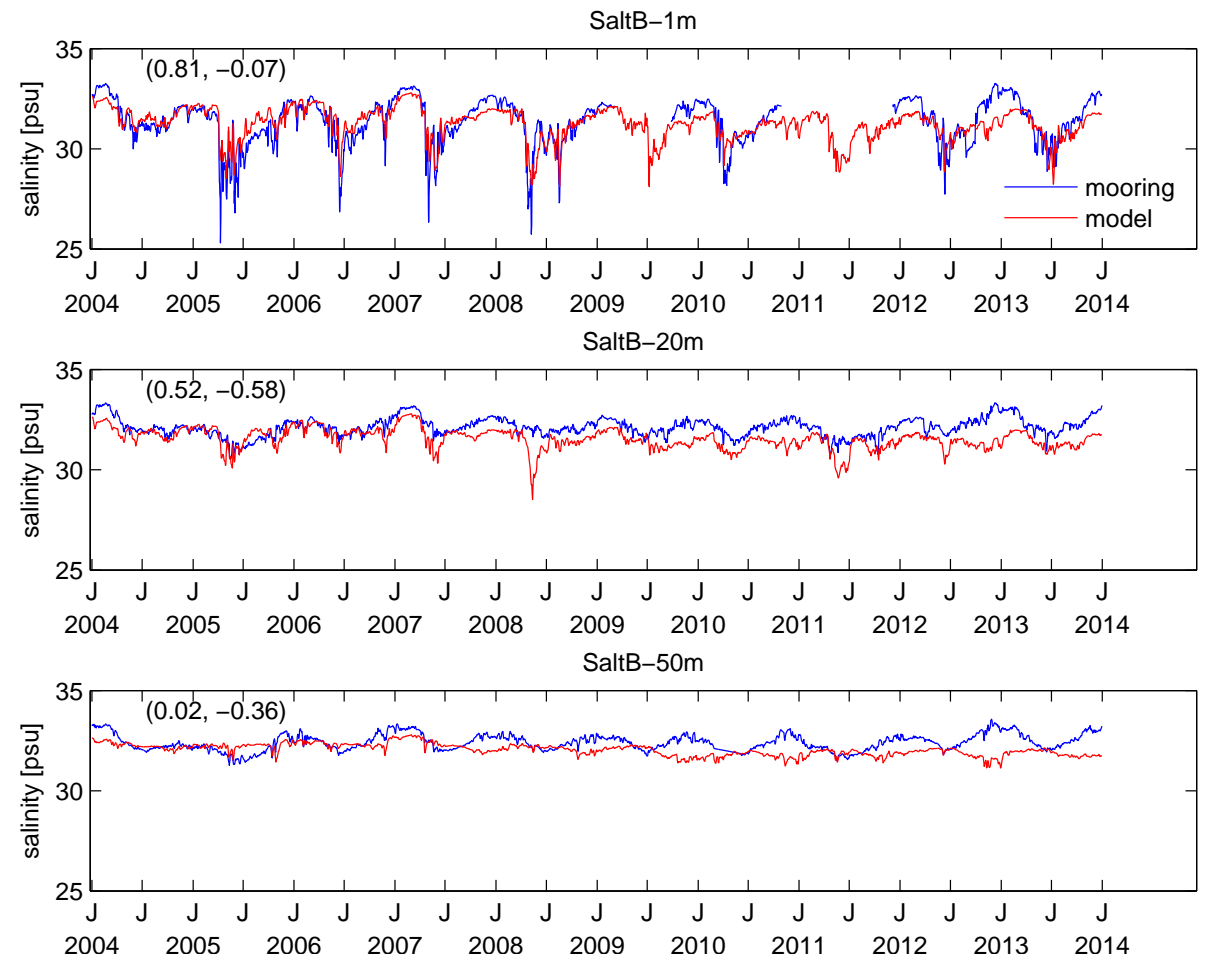

Figure 6. Comparison of observed (mooring) and simulated salinity time series at NERACOOS mooring B. Linear correlation coefficients $(r)$ and mean bias $(b)$ are shown in parentheses $(r, b)$, respectively, in each panel.

-20 and $-50 \mathrm{~m}$ ) are controlled by the vertical mixing and advection. The fact that the model generally tracks subsurface temperature series suggests that the turbulence and advection processes are realistically simulated by the model. Several sources may contribute to the larger misfit in modelsimulated subsurface temperature fields. These include the model's spatial resolution, the sensitivity of turbulence closure schemes (we used the Mellow-Yamada scheme in this study), and water mass biases inherited from the global model. It is our intention to further improve this model and make the model output available to the community at large.

Modeled salinity time series were also compared with buoy observations (Fig. 6 for Buoy B). While the model generally captures the observed salinity variations over the 10 year period, the misfits between simulated and observed values are noted. The largest surface salinity difference is seen in spring 2013, with a discrepancy of 3 units. In other periods, the misfits between model and observation are around 1 unit. Such differences in salinity are likely related to the model resolution. Early studies (e.g., Fong and Geyer, 2002) show the characteristic length scale associated with river plumes is typically $O(1 \mathrm{~km})$, suggesting a more accurate salinity simulation requires a finer model resolution than what was used in this study. This caveat is left for future improvement with nested sub-regional high-resolution models, such as the high-resolution model studies reported by $\mathrm{He}$ et al. (2008) and Chen and He (2010).

\subsubsection{Long-term mean depth-averaged shelf-current}

Lentz (2008a) investigated depth-averaged shelf currents at 14 historical mooring sites cross the MAB. Mean velocity vectors were computed by time averaging over $>200$ days of data. As Lentz (2008a) indicated, setting 200 days as the minimum duration for such averaging allows the mean current estimates to have an accuracy of $1 \mathrm{~cm} \mathrm{~s}^{-1}$. The resulting depth-average mean velocities at all sites are equatorward and approximately along-isobath. For a direct comparison, we used detided output of the MABGOM model, sampled the simulated depth-average currents at the same 14 mooring locations and averaged them over the 10-year simulation duration. This comparison (Fig. 7) shows the MABGOM model captures the uniformly southwestward motions at all 14 mooring sites. Both the observation and model show that the largest mean current is off Georges Bank, moving at $0.1 \mathrm{~m} \mathrm{~s}^{-1}$. The smallest current is nearshore by Delaware Bay, moving at about $0.03 \mathrm{~m} \mathrm{~s}^{-1}$. Differences in speed and direction are present for each pair of velocity comparisons. This is in part due to the model resolution. Overall, it is encouraging to see that the model is capable of reproducing the mean shelf circulation structure correctly.

\subsection{Mean circulation}

Given that the MABGOM model hindcast can produce a credible shelf circulation hindcast, we next use the space- 


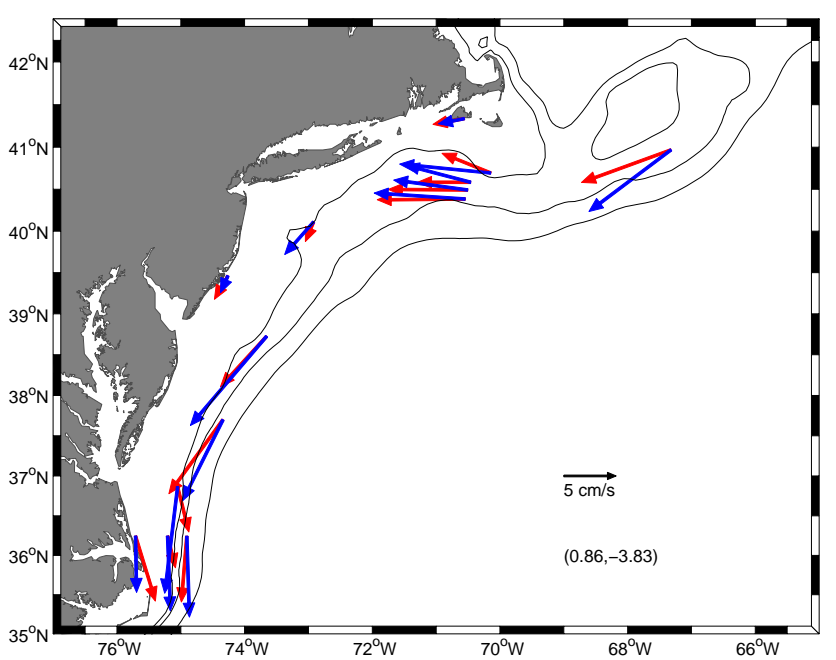

Figure 7. The comparison between observed (red; Lentz, 2008a) and MABGOM simulated (blue) mean along-shelf, depth-averaged currents. Amplitude and angle of complex correlation between the model and observation are shown in the parentheses (amplitude, angle).

and time-continuous model solutions to depict the domainwide mean circulation fields. As discussed earlier, modelsimulated state variables were temporally averaged from 1 January 2004 to 31 December 2013 to calculate the mean circulation.

\subsubsection{Mean circulation fields}

The temporal means and standard deviations of near surface (vertical layer 36), near bottom (vertical layer 2), mid-depth (vertical layer 18) and depth-averaged velocity fields, along with their respective standard deviations, highlight the spatial complexity of MABGOM shelf circulation (Fig. 8). Threedimensionality arises from geographic factors such as blocking by capes, coastal changes, and nearshore penetration of deep isobaths, as well as from the effects of baroclinicity and surface and bottom Ekman layers. The mid-depth and depthaveraged velocity fields are similar, showing the general nature of the mean currents exclusive of the Ekman layer effects.

MABGOM model-simulated mean surface currents (Fig. 8a) are consistent with the present knowledge of regional oceanography. Known circulation features are well represented, including inflow from the Scotian Shelf, cyclonic circulation in the GOM, anticyclonic circulation on Georges Bank, and equatorward (southwestward) mean shelf flow over the MAB. Also visible is the region near Cape Hatteras where southwestward-moving MAB shelf waters converge with northward-moving South Atlantic Bight (SAB) and Gulf Stream (GS) waters. While there is a clear GS flow axis, abundant mesoscale eddy fields strongly perturb its mean velocity state. The standard deviations of the velocity field are greatest in the GS/Slope Sea and shelf break area, where meanders, eddies, and cross-shelf exchanges cause 20-50\% fluctuations in speed.

The mean bottom current map (Fig. 8b) shows that velocities are much weaker than surface velocities, which is presumably due to bottom friction. Additionally, in contrast to the northward-moving GS surface flow, the bottom flow beneath the GS is moving equatorward. This is part of the deep western boundary current that constituents the lower limb of the Atlantic Meridional Overturning Circulation (e.g., Hogg, 1983; Pickart and Smethie, 1993).

The depth-averaged current field (Fig. 8d) is similar to the mid-depth (layer 18) current field (Fig. 8c), and shows a clear cyclonic gyre in the Slope Sea between the shelf break and the GS. This circulation feature is consistent with the concept of a "slope water gyre", which was first proposed by Csanady and Hamilton (1988) based on observational analyses.

\subsubsection{Mean velocity and thermohaline structure}

Mean shelf temperature, salinity, and velocity were sampled along five cross-shelf transects (Fig. 9) off Cape Cod, Long Island, New Jersey, Maryland and Cape Hatteras, North Carolina (see locations in Fig. 1). For illustration purposes, the mean velocity fields were rotated into the normal and tangential directions of each transect, precisely reproducing alongshore and cross-shelf velocity components.

Mean temperature transects (Fig. 9, column 1) show increasing temperature from north to south. The mean surface temperature difference between North Carolina and Cape Cod transects is $\sim 8-10^{\circ} \mathrm{C}$. Stronger tidal mixing off Cape Cod significantly reduces thermal stratification in the area (He and Wilkin, 2006) as opposed to other transects, where the thermocline can be identified at $\sim 20 \mathrm{~m}$ below the surface. One distinctive temperature feature is the near-bottom "cold pool" extending from the Cape Cod transect to the Maryland transect, the formation of which is largely due to the persistence of winter water as the upper water column undergoes seasonal heating and re-stratification (e.g., Houghton et al., 1982).

Large (up to 5 unit) cross-shelf salinity contrasts are evident along the entire shelf (Fig. 9, column 2). River plumes along the coast can extend to the mid-shelf and even the shelfbreak area, where they are mixed with the saltier slope water. The tilted salinity front is a common feature at the MAB shelf break, with the upper (lower) layer of the front moving offshore (onshore). The subsurface salinity onshore intrusion has been examined by Lentz (2003), which suggested multiple potential contributors, including processes of wind forcing, eddy activity, and double diffusion.

Along-shelf velocity (Fig. 9, column 3) shows a consistent southwestward (equatorward) flow throughout the entire MAB shelf. Northward flows are seen only in the offshore area of the southernmost section (i.e., the North Carolina transect). At all five transects, the maximum alongshore 

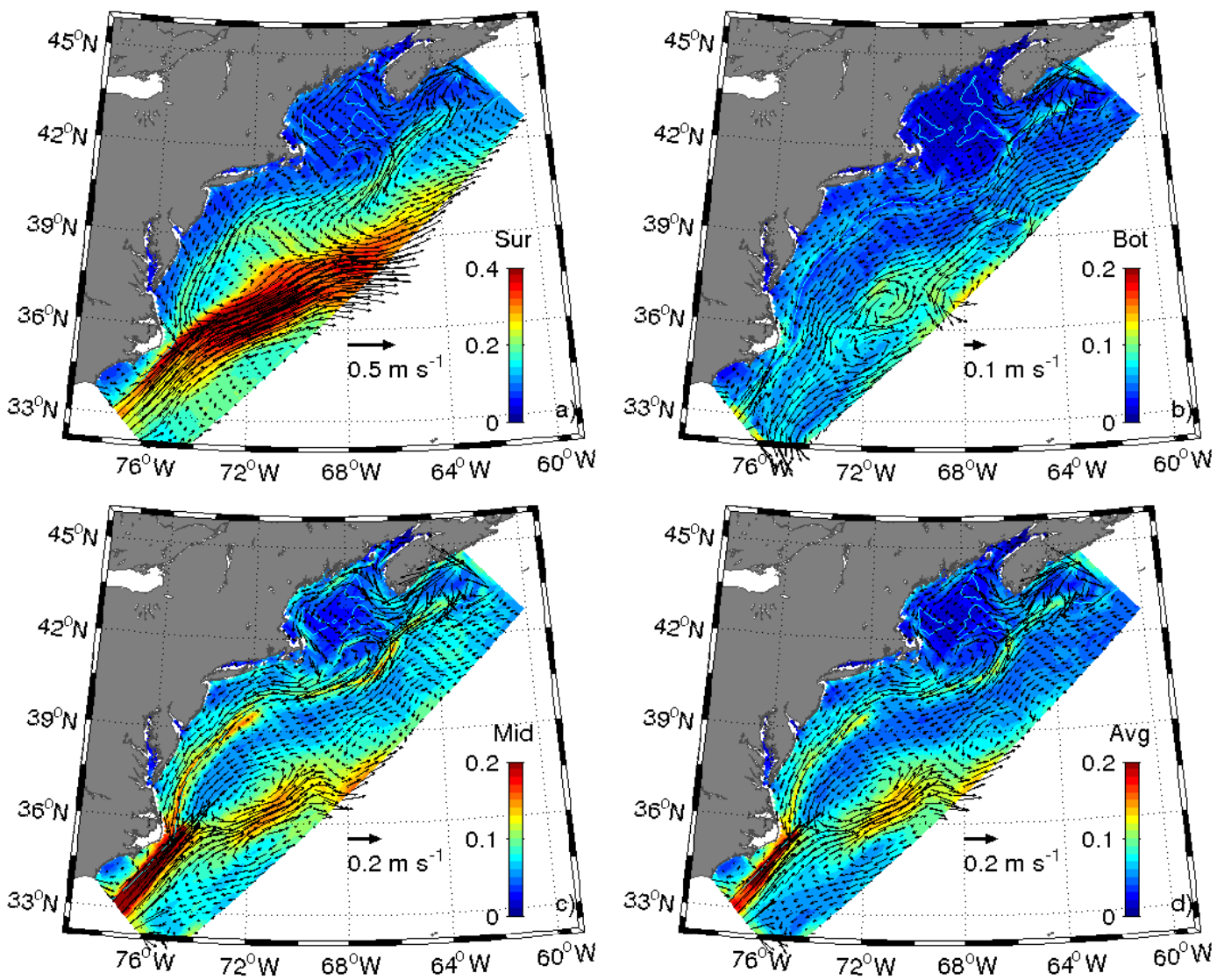

Figure 8. Domain-wide mean velocity fields (vectors) and their associated speed standard deviations (color contour) at the surface (a), bottom (b), and mid-depth (c). Depth-averaged velocity field is shown in (d). Near-surface currents are larger than those near the bottom; note scale changes.

flow is seen at the shelf break, with the highest speed of $0.25 \mathrm{~m} \mathrm{~s}^{-1}$. This is the shelfbreak jet, documented by earlier studies (e.g., Chen and He, 2010; Gawarkiewicz et al., 2001, 2004; Linder and Gawarkiewicz, 1998). Mean cross-shelf velocity maps (Fig. 9, column 4) offer further insights into the spatial extent of onshore and offshore flow and how the shelf waters interact with the deep ocean. Compared to the alongshore flow, the magnitude of cross-shelf flow is much weaker and exhibits more complex spatial patterns. Multiple onshore and offshore flow segments are seen at all transects, especially near the bottom. For example, it was found that the cross-shelf current along the Long Island transect is moving shoreward (seaward) at depths shallower (deeper) than $50 \mathrm{~m}$. The resulting bottom divergence is consistent with both theoretical model results of Lentz (2008a) and drifter trajectory observations of Bumpus (1965). We also note that near the shelf break there is a convergence of seaward shelf flow and shoreward deep ocean flow. A similar bottom divergence pattern is also seen off New Jersey and Maryland transects at $\sim 50 \mathrm{~m}$ isobath, albeit with much weaker magnitude. Interested readers are referred to Lentz (2008a) for the theoretical reasoning on why the bottom divergence occurs.

\section{Discussion}

\subsection{Mean mixed layer depth}

The ocean mixed layer depth (MLD) is an important parameter that accounts for upper ocean physical and biological properties, air-sea interaction, and long-term climate change. Given that the MABGOM is a coastal region supporting many important biogeochemical processes and experiencing climate regime shifts (Greene and Pershing, 2007), we used the model hindcast fields to estimate the mean MLD for the region. We followed the approach of Monterey and Levitus (1997) and defined the MDL as the physical depth at which the ambient temperature within a profile is within $0.5^{\circ} \mathrm{C}$ of the sea surface temperature (Fig. 10). It is noted that MLD cannot be identified in regions with strong tidal mixing, such as Georges Bank, Nantucket Shoals, and some shallow estuaries. For most coastal areas, the long-term mean MLDs are $10-15 \mathrm{~m}$. Embedded in this long-term mean are strong seasonal variations in the MLD fields. In winter, water columns over most coastal regions are well mixed, except some deep basins in the GOM and shelf edge in the MAB. The intrusion of warm slope water onto the MAB shelf may 

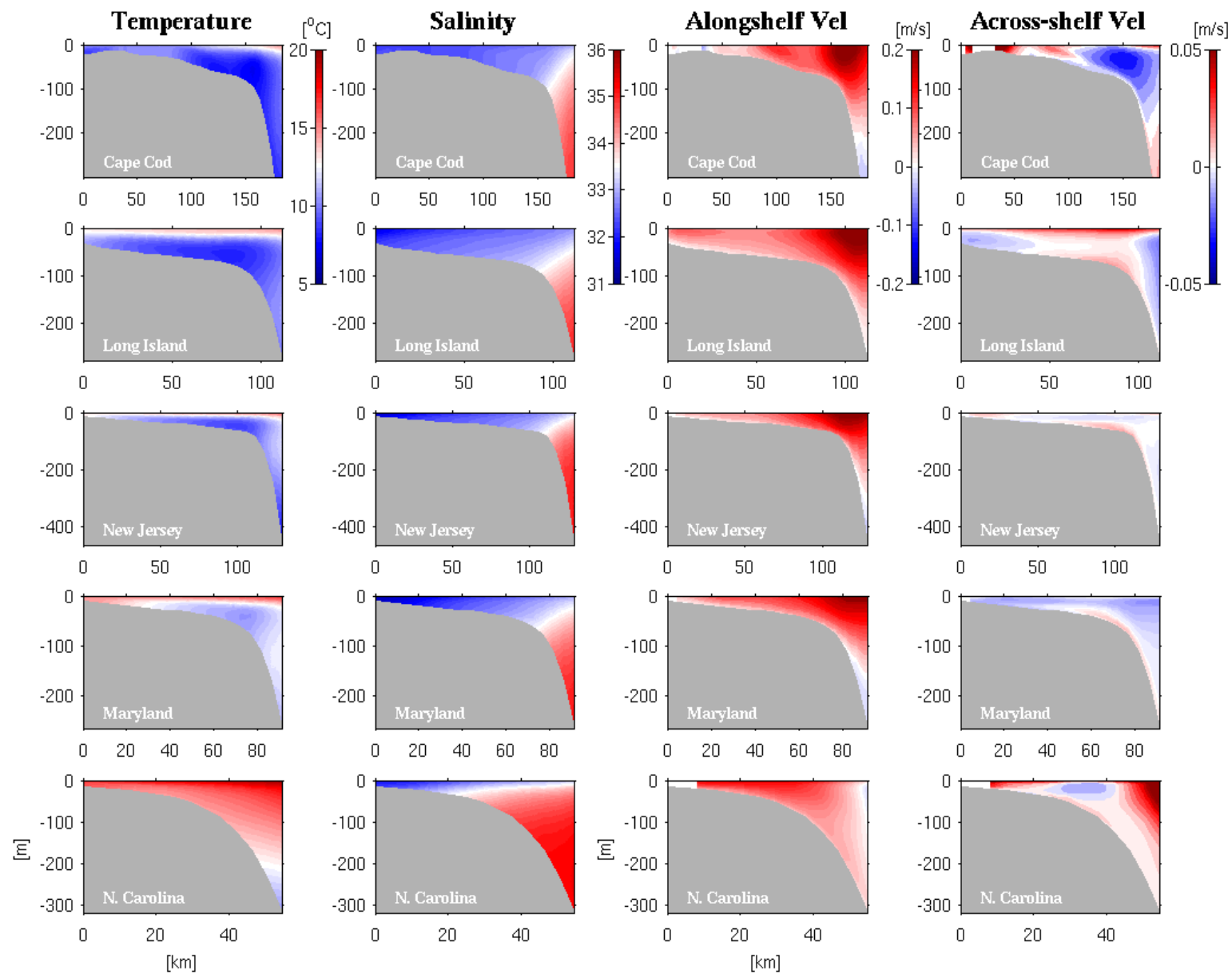

Figure 9. Mean cross-shelf transects (top transect to bottom transect is north to south) of temperature, salinity, alongshore and cross-shelf velocity. For velocity components, positive (red color) indicates equatorward and offshore, and negative (blue color) indicates poleward and onshore.

restratify the shelf water in winter. During spring and summer, seasonal stratification develops, and the MLDs are 5$15 \mathrm{~m}$ over the entire shelf region. In fall, increased storm events break down the seasonal thermocline and the MLDs start deepening. Strong tidal mixing in the GoM in combination of atmospheric forcing can deepen the MLD up to $100 \mathrm{~m}$. We note that the MLD depends on the method of calculation, and it is anticipated that these values will change using a different definition of MLD (Kara et al., 2000).

\subsection{Mean transport}

Quantifying the alongshore transport between different coastal segments and the cross-shelf exchange between the shelf sea and the Slope Sea has been a long-term objective of regional circulation studies (e.g., Beardsley and Boicourt, 1981; Fratantoni et al., 2001; Loder et al., 1998; Lozier and Gawarkiewicz, 2001). With space- and time-continuous circulation hindcast fields, we can explore this problem from a numerical modeling perspective. We first divided the $200 \mathrm{~m}$ isobath that defines the shelf-slope boundary into seven segments from North Carolina to Nova Scotia. Transports across this isobath were used to assess water exchange between the MABGOM coastal sea and the Slope Sea. Every segment is $200 \mathrm{~km}$ long except for the Georges Bank to Scotian Shelf segment, which is $600 \mathrm{~km}$ long to include the entire seaward perimeter. We then selected in the model domain from north to south seven cross-shelf transects, extending from the coast to the $200 \mathrm{~m}$ isobaths, to calculate the along-shelf transport.

Simulated three-dimensional velocity fields were rotated into the normal and tangential components based on the local orientations of each transect and segment. The normal component of velocity $U_{\mathrm{N}}$ was then integrated with local depth $Z$ and local transect/segment length $S$ to compute the volume transport according to

$Q=\int_{0}^{s_{o}} \int_{-H}^{\eta} u_{\mathrm{N}}(s, z) \mathrm{d} s \mathrm{~d} z$. 

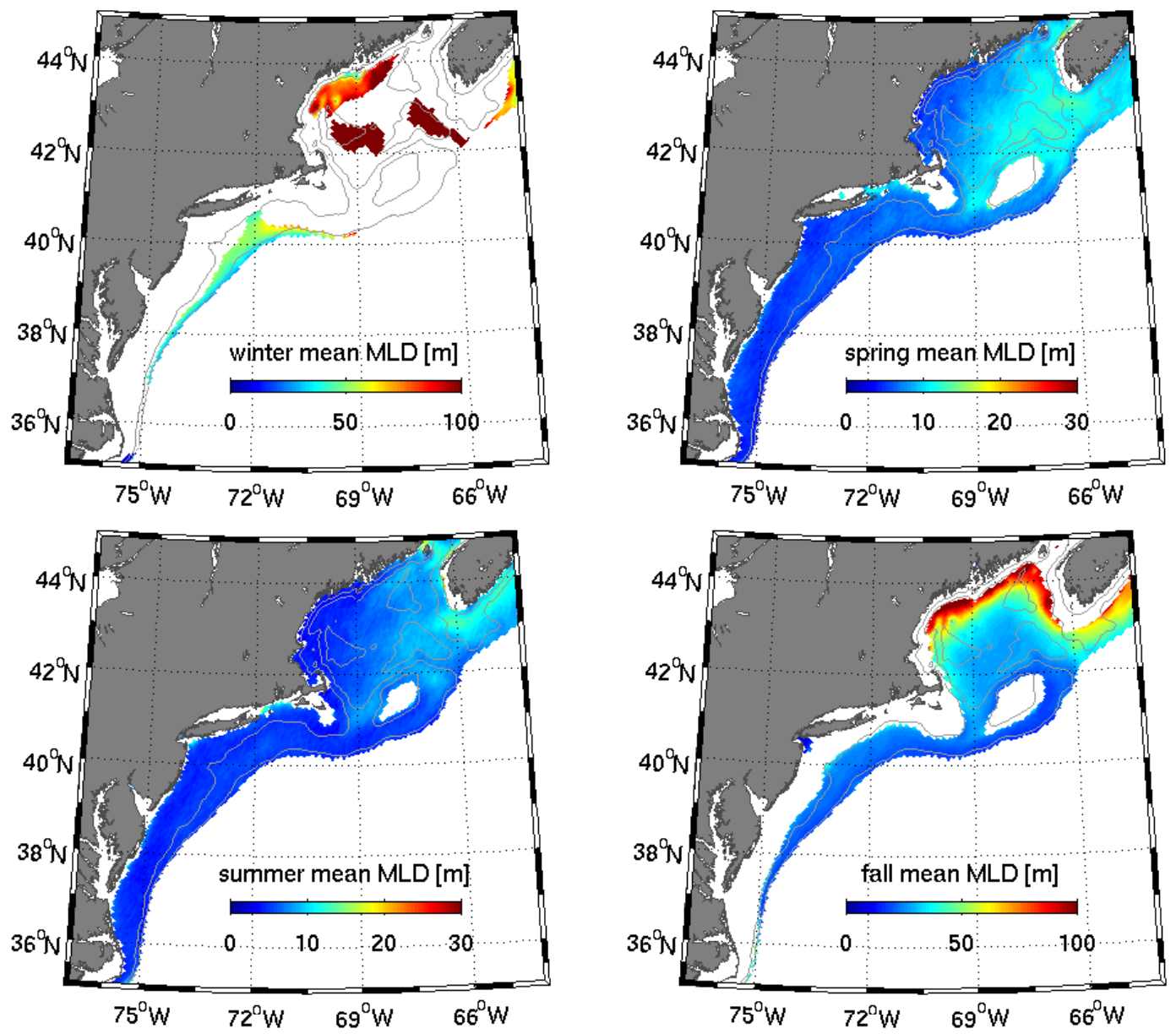

Figure 10. Simulated seasonal mean mixed layer depth $(\mathrm{m})$ over the continental shelf $(<200 \mathrm{~m})$ in the MABGOM domain. Four seasons are defined as follows: January-March (winter), April-June (spring), July-September (summer), October-December (fall). 50, 100, and 200 m isobaths are shown.

We calculated both mean transport values and their standard deviations (SDs) over the 10-year simulation. Together these values constitute a mean volume budget estimate for the MABGOM coastal ocean (Fig. 11).

In the along-shelf direction, the mean transport values experience a gradual downstream reduction, decreasing from $2.33 \mathrm{~Sv}$ along the Nova Scotia transect to $0.52 \mathrm{~Sv}$ along the Cape Cod transect, and further to $0.22 \mathrm{~Sv}$ along the North Carolina transect. The results here are largely consistent with volume estimates by Lentz (2008a) and the "leaking" shelf concept proposed by Lozier and Gawarkiewicz (2001). SDs of these along-shelf mean transport values are of the same order of magnitude, implying along-shelf flow reversals are possible subject to different local (e.g., wind) and open ocean forcing scenarios. For instance, both satellite observations and MABGOM model simulations (not shown) indicate a large warm-core eddy impinging upon the MAB shelf break in summer 2006, resulting in a strong northeastward shelf current during that period (Chen et al., 2014).
Volume variations of the along-shelf transport are balanced by cross-shelf water mass exchanges. Over the 10-year analysis period, the mean cross-shelf transports across the $200 \mathrm{~m}$ isobath were seaward. In particular, the mean crossshelf transports off Cape Hatteras and the Gulf of Maine are much larger than others, signifying they are important sites for shelf water export. In the MAB, the cross-shelf transports are smaller, but exports at the southern New England and New Jersey-Delaware shelf break are larger. On average, a total of $3.03 \mathrm{~Sv}$ of coastal water is transported from the shelf to the open ocean.

It is worth noting that these cross-shelf transports are characterized by very small means and significantly larger SDs. These SDs are at least an order of magnitude larger than the means, suggesting highly variable shelf-deep ocean exchange processes are at work. Presumably, such exchanges are closely related to eddy activities that often occur in these areas. The meandering of the shelfbreak front and resultant shelfbreak eddies, and the impingement of Gulf Stream warm core rings (WCRs) all contribute to the highly variable 


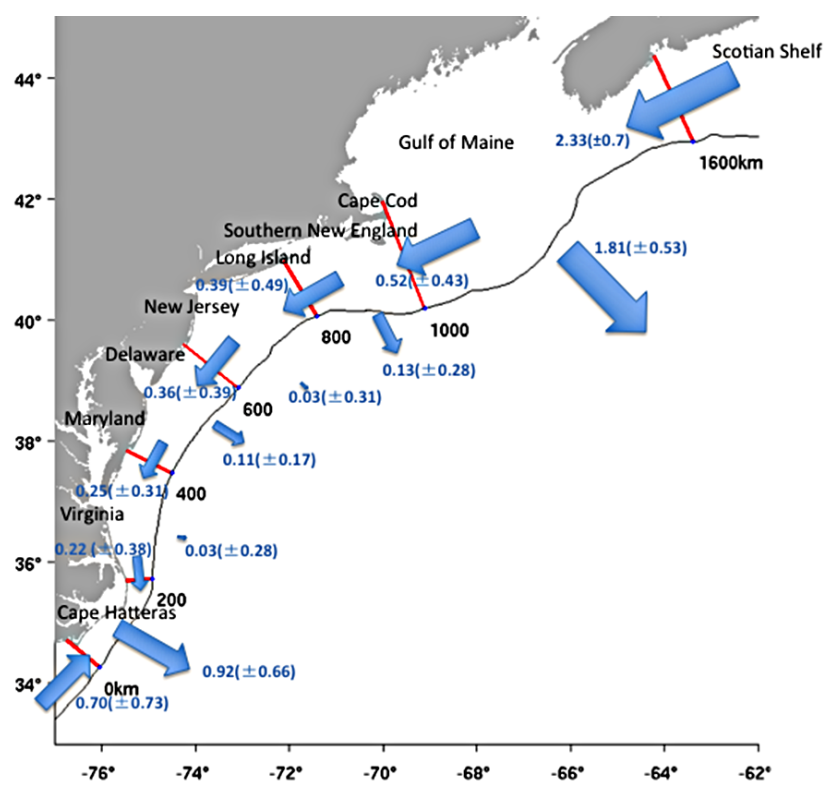

Figure 11. A schematic showing the mean circulation pattern in the MAB and GOM. The means (in Sv) and SDs (in parentheses) of transports (blue arrows) across transects in the model domain are shown.

shelf-slope exchange process. Using a high-resolution nested model based on current model, we have focused on the shelfbreak frontal system and discussed the cross-shelf process (Chen and He, 2010). The variability appeared in the second mode of EOF analysis of cross-shelf velocity is more likely related to eddy activities. In another study on a large WCR in 2006, we found that, over a timescale of 1 week, the WCR can significantly change the cross-shelf exchange of water mass, heat and salt (Chen et al., 2014). Other work also reported the significant role of eddy activities in the cross-shelf exchange (e.g., Gawarkiewicz et al., 2001, 2004; Joyce et al., 1992). Measuring the cross-shelf transport at these locations will therefore be very challenging. A carefully designed observational array is needed to resolve circulation variability in order to achieve statistically robust in situ transport measurements.

\subsection{Mean dynamical balances along the $200 \mathrm{~m}$ isobath}

To further understand the circulation dynamics associated with transport across the $200 \mathrm{~m}$ isobath, we performed termby-term depth-averaged momentum balance analysis. Each momentum term was averaged over the entire 10-year model analysis period. They were interpolated onto the $200 \mathrm{~m}$ isobath, and then rotated into the along- and cross-isobath directions according to local bathymetric orientation.

One immediate estimate this allowed us to make is the mean sea level gradient along the $200 \mathrm{~m}$ isobath, which can be computed according to

$$
\frac{\Delta \eta}{\Delta L}=-\frac{1}{g S} \int_{0}^{S}\left(-\frac{1}{\rho} \frac{\partial P}{\partial l}\right) \mathrm{d} l=2.24 \times 10^{-7},
$$

where $\partial P / \partial l$ is the temporal mean pressure gradient from the model, and $S$ is the along-isobath distance of the $200 \mathrm{~m}$ isobath in the domain. This sea level gradient is consistent with the value estimated by Xu and Oey (2011), which reported a slope of $4.8 \times 10^{-8}$ with a range of $10^{-7}$, and is also consistent with the estimate by Zhang et al. (2011), which is $0.2-2.5 \times 10^{-7}$. It is equivalent to a $0.36 \mathrm{~m}$ mean sea level difference over the $1600 \mathrm{~km}$ distance from the Nova Scotia shelf to the North Carolina shelf, arguably contributing to the equatorward mean shelf circulation.

As expected, geostrophy dominates the dynamical balance in both the along- and cross-isobath directions. The residue of the pressure gradient term plus the Coriolis term constitutes the ageostrophic component, which is responsible for smaller-scale circulation variability in the study domain. Contributions to the ageostrophic component come from the nonlinear advection term, surface and bottom stress terms, and horizontal viscosity term, as presented together in Fig. 12. In both the along- and cross-isobath $200 \mathrm{~m}$ directions, the ageostrophic term is largely balanced by nonlinear advection. This is especially the case off Cape Hatteras and Georges Bank, where currents are very energetic. Compared to advection, the combined contribution of horizontal viscosity and stress (the sum of surface and bottom stress) to the ageostrophic term are, in general, an order of magnitude smaller.

\section{Summary}

A nested regional ocean model was developed to hindcast coastal circulation over the Middle Atlantic Bight and Gulf of Maine (MABGOM) shelf from 2004 to 2013. This hindcast model was nested inside the data assimilative global HYCOM/NCODA circulation analysis. At its surface and lateral boundaries, it was driven by realistic atmospheric forcing, tidal harmonics and observed river runoff. Our goal for the MABGOM model is to produce a more accurate model representation of regional circulation by adding more complete coastal dynamics (i.e., river discharge and tidal forcing, which are absent in the global model) to the regional model and correcting biases in the global model. Such a regional model can then provide dynamically consistent open boundary conditions (OBCs) for higher-resolution nested models to investigate more specific research questions in each subregion. For example, the MABGOM model had provided OBCs for a Gulf of Maine coupled biophysical model (He et al., 2008; Li et al., 2009) and a high-resolution circulation model focusing on the shelfbreak processes in the Middle Atlantic Bight (Chen and He, 2010). 

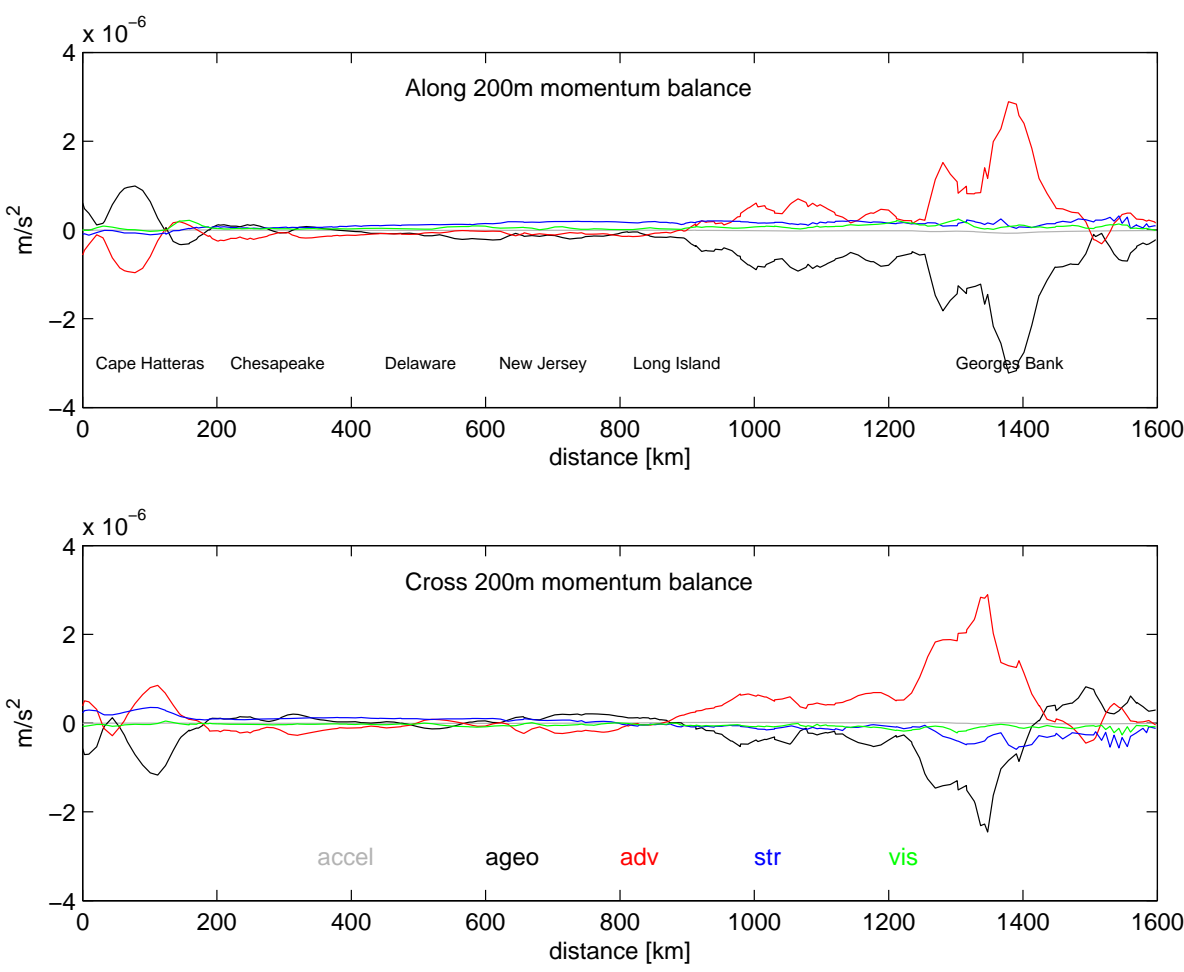

Figure 12. Mean momentum term-by-term balances in along (upper) and across (lower) the $200 \mathrm{~m}$ isobath directions. Momentum terms in the figure represent time rate of change (accel), ageostrophic circulation (ageo), advection (adv), surface and bottom stress (str), and horizontal viscosity (vis).

Extensive model-data comparisons indicate this MABGOM model is capable of reproducing the temporal and spatial variability of regional circulation. We also examined comparisons between observations and HYCOM results to highlight the benefits of our own modeling approach. While surface temperature comparisons are very reasonable, we found clear mismatch in the subsurface thermal structures generated by HYCOM/NCODA's surface performance. HYCOM/NCODA also failed to resolve the surface variability due to the missing freshwater discharge from the coast (not shown). The comparison of depth-averaged current further reveals the problem of this global model (not shown). HYCOM/NCODA systematically underestimates the mean velocity vectors, and at many places fails to reproduce the equatorward along-shelf flow. Using the time- and spacecontinuous circulation hindcast fields from January 2004 to December 2013, we further described the mean coastal circulation and its three-dimensional structures. The along-shelf and cross-shelf transports were quantified. In the latter case, the $200 \mathrm{~m}$ isobath was used as the boundary between the shelf sea and the deep ocean. Our calculations confirmed the presence of the equatorward alongshore current. The alongshore transport values gradually decrease from north to south, supporting the "leaky shelf" concept proposed by earlier observational studies. The shelfbreak segments offshore of the Gulf of Maine and Cape Hatteras appear to be the major sites of shelfwater export. Other segments along the $200 \mathrm{~m}$ isobath are characterized by significantly large cross-shelf transport variability, with standard deviations up to an order of magnitude larger than the means. The momentum analysis further indicates that the along-shelf sea level gradient from Nova Scotia to Cape Hatteras is about $0.36 \mathrm{~m}$. Although measuring such a sea level gradient would be technically challenging, such a pressure gradient can play an important role in driving the equatorward mean shelf current. The nonlinear advection dominates the ageostrophic circulation in the crossisobath direction, whereas the advection, stress and horizontal viscosity terms all contribute ageostrophic circulation in the along-isobath direction.

While the mean shelf circulation is the focus of this study, we note that the hindcast solutions reveal that significant interannual variations are present in the MABGOM shelf circulation. We leave the discussion of those to a future study. Admittedly, this MABGOM model model is still of coarse resolution, so our discussions on the shelf water transport have emphasized the mean flow advection. This is not to say that transport associated with smaller-scale wave, turbulence, and transitory events such as the shelfbreak secondary circulation (e.g., Linder et al., 2004) are not important. Deterministic predictions of circulation and transport in this area will clearly require advanced observational infrastructure and a 
higher-resolution circulation model together with sophisticated techniques for data assimilation.

Acknowledgements. We acknowledge research support provided through ONR grant N00014-06-1-0739, NASA grants NNX07AF62G and NNX13AD80G, NSF grant 1435602, and the NC Ocean Energy Project. Comments from G. Gawarkiewicz on the manuscript are much appreciated. We are indebted to S. Lentz, D. McGillicuddy and J. Wilkin for valuable discussions and suggestions throughout the course of this study. We thank AVISO and NERACOOS for serving their data online.

Edited by: E. J. M. Delhez

\section{References}

Aikman, F., Ou, H. W., and Houghton, R. W.: Current variability across the New-England continental shelf-break and slope, Cont. Shelf Res., 8, 625-651, 1988.

Beardsley, R. C. and Boicourt, W. C.: On Estuarine and ContinentalShelf Circulation in the Middle Atlantic Bight, MIT Press, Cambridge, MA, 1981.

Beardsley, R. C., Chapman, D. C., Brink, K. H., Ramp, S. R., and Schlitz, R.: The Nantucket Shoals Flux Experiment (NSFE79). Part 1, A basic description of the current and temperature variability, J. Phys. Oceanogr., 15, 713-748, 1985.

Brink, K. H.: Coastal-trapped waves and wind-driven currents over the continental shelf, Annu. Rev. Fluid Mech., 23, 389-412, 1991.

Brooks, D. A.: Vernal circulation in the Gulf of Maine, J. Geophys. Res.-Oceans, 90, 4687-4706, 1985.

Bumpus, D. F.: Residual drift along the bottom on the continental shelf in the Middle Atlantic Bight area, Limnol. Oceanogr., 10, R50-R53, 1965.

Chapman, D. C. and Beardsley, B. C.: On the origin of shelf water in the Middle Atlantic Bight, J. Phys. Oceanogr., 19, 384-391, 1989.

Chassignet, E. P., Hurlburt, H. E., Smedstad, O. M., Halliwell, G. R., Hogan, P. J., Wallcraft, A. J., Baraille, R., and Bleck, R.: The HYCOM (HYbrid Coordinate Ocean Model) data assimilative system, J. Marine Syst., 65, 60-83, 2006.

Chen, K. and He, R.: Numerical investigation of the Middle Atlantic Bight shelfbreak frontal circulation using a high-resolution ocean hindcast model, J. Phys. Oceanogr., 40, 949-964, 2010.

Chen, K., He, R., Powell, B. S., Gawarkiewicz, G. G., Moore, A. M., and Arango, H. G.: Data assimilative modeling investigation of Gulf Stream Warm Core Ring interaction with continental shelf and slope circulation, J. Geophys. Res.-Oceans, 119, 5968-5991, doi:10.1002/2014JC009898, 2014.

Churchill, J. H., Cornillon, P. C., and Milkowski, G. W.: A cyclonic eddy and shelf-slope exchange associated with a Gulf Stream warm-core ring, J. Geophys. Res., 91, 9615-9623, 1986.

Csanady, G. T.: Mean circulation in shallow seas, J. Geophys. Res.Oceans, 81, 5389-5399, 1976.

Csanady, G. T. and Hamilton, P.: Circulaton of the slope water, Cont. Shelf Res., 8, 565-624, 1988.
Curry, R.: A database of hydrographic profiles and tools for climatological analysis, Woods Hole Oceanographic Institution, 81 pp., 2001.

Fairall, C. W., Bradley, E. F., Hare, J. E., Grachev, A. A., and Edson, J.: Bulk parameterization of air-sea fluxes: updates and verification for the COARE algorithm, J. Climate, 16, 571-591, 2003.

Flather, R. A.: A tidal model of the northwest European continental shelf, Mem. Soc. R. Sci. Liege, 6, 141-164, 1976.

Fong, D. A. and Geyer, W. R.: The alongshore transport of freshwater in a surface-trapped river plume, J. Phys. Oceanogr., 32, 957-972, 2002.

Fratantoni, P. S., Pickart, R. S., Torres, D. J., and Scotti, A.: Mean structure and dynamics of the shelfbreak jet in the Middle Atlantic Bight during fall and winter, J. Phys. Oceanogr., 31, 21352156, 2001.

Garvine, R. W., Wong, K. C., Gawarkiewicz, G., McCarthy, R. K., Houghton, R. W., and Aikman, F.: The morphology of shelfbreak eddies, J. Geophys. Res., 93, 15593-15607, 1988.

Gawarkiewicz, G., Bahr, F., Beardsley, R. C., and Brink, K. H.: Interaction of a slope eddy with the shelfbreak front in the Middle Atlantic Bight*, J. Phys. Oceanogr., 31, 2783-2796, 2001.

Gawarkiewicz, G., Brink, K., Bahr, F., Beardsley, R., and Caruso, M.: A large-amplitude meander of the shelfbreak front during summer south of New England: observations from the Shelfbreak PRIMER experiment, J. Geophys. Res., 109, C03006, doi:10.1029/2002JC001468, 2004.

Gill, A. E.: Atmosphere-Ocean Dynamics, Academic, San Diego, California, 1990.

Greene, C. H. and Pershing, A. J.: Climate drives sea change, Science, 315, 1084-1085, 2007.

He, R. and Weisberg, R. H.: West Florida shelf circulation and temperature budget for the 1999 spring transition, Cont. Shelf. Res., 22, 719-748, 2002.

He, R. and Wilkin, J. L.: Barotropic tides on the southeast New England shelf: A view from a hybrid data assimilative modeling approach, J. Geophys. Res., 111, C08002, doi:10.1029/2005JC003254, 2006.

He, R., McGillicuddy, D. J., Keafer, B. A., and Anderson, D. M.: Historic 2005 toxic bloom of Alexandrium fundyense in the western Gulf of Maine: 2. Coupled biophysical numerical modeling, J Geophys. Res.-Oceans, 113, C07040, 2008.

Hogg, N. G.: A note on the deep circulation of the western North Atlantic: its nature and causes, Deep-Sea Res., 30, 945-961, 1983.

Houghton, R. W., Schlitz, R., Beardsley, R. C., Butman, B., and Chamberlin, J. L.: The Middle Atlantic Bight cold pool: evolution of the temperature structure during summer 1979, J. Phys. Oceanogr., 12, 1019-1029, 1982.

Houghton, R. W., Olson, D. B., and Celone, P. J.: Observation of an anticyclonic eddy near the continental shelf break south of New England, J. Phys. Oceanogr., 16, 60-71, 1986.

Joyce, T. M., Bishop, J. K. B., and Brown, O. B.: Observations of offshore shelf-water transport induced by a warm-core ring, Deep-Sea Res., 39, 97-113, 1992.

Joyce, T. M., Deser, C., and Spall, M. A.: The relation between decadal variability of subtropical mode water and the North Atlantic Oscillation*, J. Climate, 13, 2550-2569, 2000. 
Kara, A. B., Rochford, P. A., and Hurlburt, H. E.: An optimal definition for ocean mixed layer depth, J. Geophys. Res.-Oceans, 105, 16803-16821, 2000.

Lentz, S. J.: A climatology of salty intrusions over the continental shelf from Georges Bank to Cape Hatteras, J. Geophys. Res., 108, 3326, doi:10.1029/2003JC001859, 2003.

Lentz, S. J.: Observations and a model of the mean circulation over the Middle Atlantic Bight continental shelf, J. Phys. Oceanogr., 38, 1203-1221, 2008a.

Lentz, S. J.: Seasonal variations in the circulation over the Middle Atlantic Bight continental shelf, J. Phys. Oceanogr., 38, 14861500,2008 b.

Linder, C. A. and Gawarkiewicz, G. G.: A climatology of the shelfbreak front in the Middle Atlantic Bight, J. Geophys. Res., 103, 18405-18423, 1998.

Linder, C. A., Gawarkiewicz, G. G., and Pickart, R. S.: Seasonal characteristics of bottom boundary layer detachment at the shelfbreak front in the Middle Atlantic Bight, J. Geophys. Res., 109, C03049, doi:10.1029/2003JC002032, 2004.

Loder, J. W., Han, G., Hannah, C. G., Greenberg, D. A., and Smith, P. C.: Hydrographic and baroclinic circulation in the Scotian Shelf region: winter vs summer, Can. J. Fish. Aquat. Sci., 54, 40-56, 1997.

Loder, J. W., Petrie, B., and Gawarkiewicz, G.: The coastal ocean off northeastern North America: a large-scale view, in: The Sea, edited by: Robinson, A. R. and Brink, K. H., 1998.

Lozier, M. S. and Gawarkiewicz, G.: Cross-frontal exchange in the Middle Atlantic Bight as evidenced by surface drifters, J. Phys. Oceanogr., 31, 2498-2510, 2001.

Luettich, R. A., Westerink, J. J., and Scheffner, N. W.: ADCIRC: an advanced three-dimensional circulation model for shelves, coasts, and estuaries, DRP-92-6, U.S. Army Engineer Waterways Experiment Station, Vicksburg, MS, 1992.

Marchesiello, P., McWilliams, J. C., and Shchepetkin, A. F.: Open boundary conditions for long-term integration of regional oceanic models, Ocean Model., 3, 1-20, 2001.
Mellor, G. L. and Yamada, T.: Development of a turbulence closure model for geophysical fluid problems, Rev. Geophys., 20, 851875, doi:10.1029/RG020i004p00851, 1982.

Monterey, G. and Levitus, S.: Seasonal variability of mixed layer depth for the world ocean, NOAA Atlas NESDIS 14, US Gov. Printing Office, Wash., D.C., 96 pp., 1997.

Pickart, R. S. and Smethie, W. M.: How does the deep western boundary current cross the Gulf Stream?, J. Phys. Oceanogr., 23, 2602-2616, 1993.

Ramp, S. R., Schlitz, R. J., and Wright, W. R.: The deep flow through the Northeast Channel, Gulf of Maine, J. Phys. Oceanogr., 15, 1790-1808, 1985.

Rio, M. H. and Hernandez, F.: A mean dynamic topography computed over the world ocean from altimetry, in situ measurements, and a geoid model, J. Geophys. Res.-Oceans, 109, C12032, doi:10.1029/2003JC002226, 2004.

Shchepetkin, A. F. and McWilliams, J. C.: Quasi-monotone advection schemes based on explicit locally adaptive diffusion, Mon Weather Rev., 126, 1541-1580, 1998.

Shchepetkin, A. F. and McWilliams, J. C.: A method for computing horizontal pressure-gradient force in an oceanic model with a non-aligned vertical coordinate, J. Geophys. Res., 108, 3090, doi:10.1029/2001JC001047, 2003.

Shchepetkin, A. F. and McWilliams, J. C.: The regional oceanic modeling system (ROMS): a split-explicit, free-surface, topography-following-coordinate oceanic model, Ocean Model., 9, 347-404, 2005.

Walsh, J. J., Biscaye, P. E., and Csanady, G. T.: The 1983-1984 Shelf Edge Exchange Processes (SEEP) - 1 experiment hypotheses and highlights, Cont. Shelf Res., 8, 435-456 1988.

$\mathrm{Xu}, \mathrm{F}$. H. and Oey, L. Y.: The origin of along-shelf pressure gradient in the Middle Atlantic Bight, J. Phys. Oceanogr., 41, 1720-1740, 2011.

Zhang, W. G., Gawarkiewicz, G. G., McGillicuddy, D. J., and Wilkin, J. L.: Climatological mean circulation at the New England shelf break, J. Phys. Oceanogr., 41, 1874-1893, 2011. 